\title{
The Conditions which Govern the Adsorption of a Tryptophan-Dependent Bacteriophage to Kaolin and Bacteria
}

\author{
By P. FILDES AND D. KAY \\ British Empire Cancer Campaign Unit for Virus Research, Sir William \\ Dunn School of Pathology, University of Oxford
}

(Received 12 March 1962)

\begin{abstract}
SUMMARY
The adsorption of a tryptophan-requiring (tryp ${ }^{+}$) hydroxymethylcytosine (HMC) phage $(\mathrm{Ox} 6)$ to bacteria has been compared with that to kaolin. In a system free from monovalent cations other than tris (2-amino2-hydroxymethylpropane-1,3-diol) buffer, adsorption in both cases was temperature-dependent and required not only tryptophan but an optimum concentration of $\mathrm{NaCl}$. The adsorption to kaolin came to an equilibrium which was determined by temperature since it depended on a preliminary activation of the phage, which process was temperature-dependent. Elution of phage adsorbed to kaolin took place to a greater or less degree on altering any one of the three requirements, $\mathrm{NaCl}$, tryptophan or temperature. In experiments with bacteria no equilibrium was reached because adsorption was followed rapidly by inactivation; no elution was demonstrable.
\end{abstract}

\section{INTRODUCTION}

It is generally agreed (cf. Luria, 1953) that the adsorption of bacteriophages to bacteria and to inanimate particles requires not only a certain ionic concentration but also in some cases the presence of 'adsorption factors'. Doubt however exists on the validity of some accepted conclusions and it was thought worth while to explore the field by methods different from those generally used. This paper gives details of the factors involved in the adsorption of a single tryptophan-requiring member of the hydroxymethylcytosine (HMC) phage group (Kay \& Fildes, 1962 a) to kaolin and to a susceptible bacterium.

\section{MATERIALS}

Tris buffer. All solutions and suspensions were made in 0.011 M-tris (2-amino-2hydroxymethylpropane-1,3-diol) buffer $(\mathrm{pH} 7 \cdot 6)+$ human serum albumin. The tris solution was sterilized by autoclaving at $120^{\circ}$ for $20 \mathrm{~min}$., cooled, and $3 \mathrm{ml} .5 \%$ human serum albumin added per litre; exceptions to this were the stocks of phage and kaolin.

The phage used was ' Ox6' (Kay \& Fildes, 1962a). This was produced in a simple glucose +ammonia medium and purified by differential centrifugation. Stocks

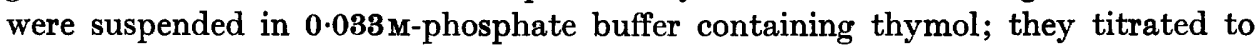
about $1 \times 10^{11}$ particles $/ \mathrm{ml}$. and for use in an experiment were normally diluted in tris buffer to final $5 \times 10^{3}$ particles $/ \mathrm{ml}$. 
The kaolin was a suspension of British Drug Houses Ltd. kaolin in 0.011 M-tris buffer containing no albumin. A heavy suspension was made and supernatant suspension removed; more buffer was then added and the procedure repeated several times to obtain a stock suspension of finer particles. This stock was not observed to alter when kept at $2^{\circ}$. In an experiment it was so diluted in $0.011 \mathrm{M}$-tris albumin that the final reading was $\mathbf{0 . 3 0 0}$ on a Hilger Spekker absorptiometer, using unfiltered light.

The bacterium used for adsorption and lawns was a clone ' $M$ ', selected from coli $518(3)$ referred to by Fildes \& Kay (1959). It was grown in nutrient broth for use as a lawn. For adsorption experiments organisms were washed twice in tris buffer + albumin and re-suspended in the same. The suspension showed a gradual loss of activity at $\mathbf{2}^{\circ}$.

DL-tryptophan. The stock was a $0.01 \mathrm{~m}$-solution in $0.002 \mathrm{M}-\mathrm{NaOH}$ with thymol added after autoclaving. Normally this was used in an experiment at a final concentration $10 \cdot 2 \mu \mathrm{g}$. L-tryptophan $/ \mathrm{ml}$.

In an adsorption experiment the various materials were distributed in one ounce screw-cap bottles. Bottles were held at the required temperature for $\mathbf{3 0} \mathrm{min}$. by immersion in water. At zero time the experiment was started by adding phage or recipient, as required, to the other materials. Samples were taken from time to time to check the input and to confirm that the phage was heat stable at the temperature used. Other samples were centrifuged and the supernatant phages assayed. The counts were plotted as $\log \%$ input at the observed times. When using kaolin there was no necessity to stop adsorption by dilution because adsorption was slow, but with bacteria the input was arranged to allow a 1/500 dilution in the same substrate without bacteria. Dilution took place at the operative temperature, usually $37^{\circ}$.

Phage assay. The assay was made by the drop method (Fildes \& Kay, 1957). It was preferable to use nutrient agar plates at least 7 days after pouring and not to heat them on a hot plate to accelerate drying of the drops. With the pipettes used four drops delivered $0.1 \mathrm{ml}$. Since the input was of the order of $5 \times 10^{3}$ particles $/ \mathrm{ml}$., $0 \cdot 1 \mathrm{ml}$. contained about 500 phage particles or $125 / \mathrm{drop}$. The nutrient agar contained $1.5 \%$ agar, $1.0 \%$ Difco Bacto nutrient broth, 0.125 $\mathrm{M}-\mathrm{NaCl}, 0.01 \mathrm{M}$-sodium citrate. Plates were seeded with sufficient coli strain ' $M$ ' in Bacto nutrient broth and all excess removed; they dried in a few minutes with the covers off. Counts were made after incubation for 4-5 hr. or overnight; a Zeiss binocular microscope was used at $\times 10$ diam. When assay of a supernatant fluid was required, $4 \mathrm{ml}$. were centrifuged in an angle centrifuge at $4000 \mathrm{rev} . / \mathrm{min}$. for $5 \mathrm{~min}$.; the sample was then removed with a Pasteur pipette from the meniscus on the near side of the tube.

\section{RESULTS}

\section{The effect of $\mathrm{NaCl}$ on the adsorption of phage Ox6 to kaolin}

Experiment 1. Two series of bottles 1 to 8 and 9 to 16 were used; all contained tryptophan; bottles 2 to 8 and 10 to 16 contained graded amounts of $\mathrm{NaCl}$ to final concentrations $0.02 \mathrm{M}$ to $0 \cdot 10 \mathrm{M}$. Bottles 9 to 16 contained kaolin. The volumes of fluid were equalized with tris buffer to $9 \mathrm{ml}$. The phage suspension suitably diluted, and the bottles were heated to $37^{\circ}$ for $20 \mathrm{~min}$. Then at zero time, phage suspension 
$\left(1.0 \mathrm{ml}\right.$.) was added to all and the bottles returned to $37^{\circ}$. Supernatant fluids from bottles 1 and 9 were assayed at zero time and all bottles (9 to 16 supernatant fluids) after $60 \mathrm{~min}$. Figure 1 shows that $0.05 \mathrm{M}-\mathrm{NaCl}$ gave the maximum degree of adsorption; in the absence of $\mathrm{NaCl}$ there was no adsorption even though tryptophan was present.

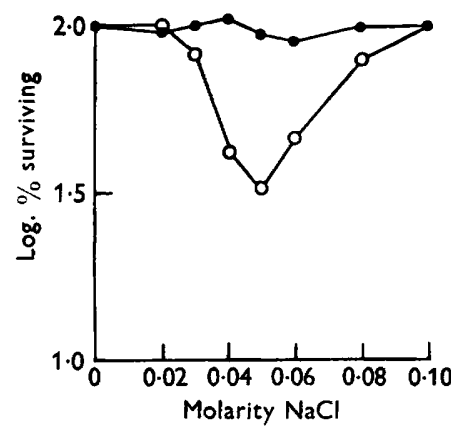

Fig. 1

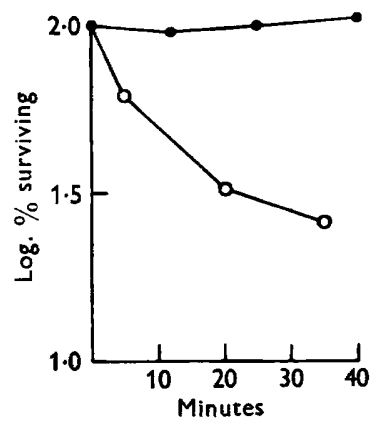

Fig. 2

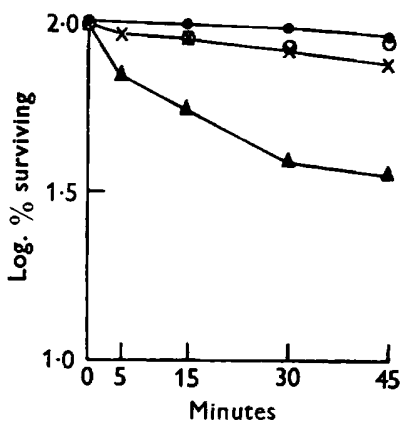

Fig. 3

Fig. 1. Titration of $\mathrm{NaCl}$ to show optimum concentration for adsorption of phage $\mathrm{Ox} 6$ to kaolin. O, No kaolin; $O$, with kaolin (supernatant phage). Both contain tryptophan. Fig. 2. Effect of tryptophan on adsorption of phage $O \times 6$ to kaolin at $40^{\circ}$. No tryptophan; $O$, with tryptophan. Both contain optimal $\mathrm{NaCl}$ and kaolin. Supernatant phage counts.

Fig. 3. Effect of temperature on adsorption of phage $0 \times 6$ to kaolin. 0 , No kaolin at $18^{\circ}$; $\times$, with kaolin at $18^{\circ}$; $O$, no kaolin at $37^{\circ} ; \boldsymbol{\Lambda}$, with kaolin at $37^{\circ}$. All contain optimal $\mathrm{NaCl}$ and tryptophan. Counts with kaolin are on supernatant phage after centrifuging.

\section{The effect of tryptophan on the adsorption of phage Ox6 to kaolin}

Experiment 2. Three bottles were used containing: (1) tris buffer $+\mathrm{NaCl}(0.05 \mathrm{M}$ final $)+$ phage; (2) tris buffer $+\mathrm{NaCl}(0.05 \mathrm{~m}$ final $)+$ kaolin + phage; (3) tris buffer + $\mathrm{NaCl}(0.05 \mathrm{M}$ final $)+$ kaolin + tryptophan + phage.

Bottle 1 was plated three times during $45 \mathrm{~min}$. to determine the average input and the supernatant fluids of the kaolin-containing bottles were plated three times to show adsorption. Figure 2 indicates the result; in the presence of optimal $\mathrm{NaCl}$ without tryptophan there was no adsorption at $40^{\circ}$, but $74 \%$ adsorption in $35 \mathrm{~min}$. in the presence of $\mathrm{NaCl}+$ tryptophan.

\section{The effect of temperature on the rates of adsorption of phage Ox6 to kaolin}

Activation. There was no measurable adsorption of phage $0 \times 6$ to kaolin at $2^{\circ}$, but adsorption was detectable at $15-20^{\circ}$. Figure 3 illustrates the difference of adsorption between $18^{\circ}$ and $37^{\circ}$. So marked an effect of temperature was not expected from the physical theory of adsorption and it was assumed that the observations had been complicated by the 'activation' of the phage by tryptophan, a process which is known in the case of coliphage $T 4$ (Anderson, 1948) to be thermally controlled. Since an increasing proportion of the phage particles is activated as the temperature rises, the rates of adsorption also increase, giving an impression that adsorption is directly influenced. 
Elution. It will be noticed that the rate of adsorption of phage $\mathrm{Ox} 6$ to kaolin declined with time and thus did not follow the course generally described as characteristic of adsorption to bacteria; with bacteria a plot of the $\log$ of the number of phage particles remaining free against time is linear. In a purely physical process of adsorption this would not be expected but rather the development gradually of a dynamic equilibrium between adsorption and elution, resulting in a more rapid adsorption at first followed by a gradual slowing. In our experience with kaolin the results are characteristic of a physical process in which, at equilibrium, the rates of adsorption and elution are equal. Only when the environment is changed to one inappropriate to the maintenance of this equilibrium are the phages permanently released.

Change in the ionic environment. In Expt. 8 each of two bottles contained tris buffer, tryptophan, $0.05 \mathrm{M}-\mathrm{NaCl}$ and phage; one bottle also contained kaolin. Adsorption was allowed to proceed for $30 \mathrm{~min}$. at $40^{\circ}$ and then $20 \mathrm{ml}$. were removed from the kaolin bottle to another containing $1.0 \mathrm{ml} .6 \mathrm{M}-\mathrm{NaCl}$. In this bottle therefore the $\mathrm{NaCl}$ was about $0.35 \mathrm{M}$. Figure 4 shows the log $\%$ phage particles surviving in the kaolin supernatant fluids at various times. On altering the $\mathrm{NaCl}$ concentration to a value well above that at which adsorption occurs, all adsorbed phage particles were immediately released. The adsorption therefore had no effect on the plating efficiency of the phage. The same result may be seen merely by plating the whole of a kaolin adsorption mixture in addition to the supernatant fluid. Although the supernatant fluid count may indicate a high degree of adsorption, the whole count is equal to the input. Thus the adsorbed phage particles in the mixture must have been released on the plate.

Change in the temperature. When phage $0 \times 6$ was adsorbed at $37^{\circ}$ and then cooled to $4^{\circ}$, any phage particles momentarily released would be liable to de-activation so that they would not be adsorbed at $4^{\circ}$. The extent of this risk depends upon the length of the period of elution and the rate of de-activation by lowered temperature. Since the former period is probably much shorter than the latter permanent elution by lowering the temperature is not likely to be marked. Figure 5 indicates that $8 \%$ of the phage particles adsorbed at $40^{\circ}$ may have been eluted by lowering the temperature to $2^{\circ}$; this is hardly significant but it is clear that continued adsorption ceased.

Change in the tryptophan concentration. Alteration in the tryptophan concentration is also liable to affect the stability of adsorbed phage. When the phage particles were adsorbed at $37^{\circ}$ in the presence of L-tryptophan $10 \mu \mathrm{g} . / \mathrm{ml}$. and then diluted 1/500 in the absence of tryptophan, active phage particles momentarily released would be exposed to L-tryptophan $0.02 \mu \mathrm{g} . / \mathrm{ml}$., a concentration below the effective value for adsorption. Again, depending on rates of de-activation (2 min. according to Anderson, 1948) and of re-adsorption, some of the phage particles will be liable to de-activation and permanent release. As shown in Fig. 6, 34\% of the particles adsorbed at $37^{\circ}$ were immediately released by decreasing the concentration of tryptophan to $0.02 \mu \mathrm{g} . / \mathrm{ml}$, i.e. they were de-activated after release, but, as the counts of the whole suspension indicate, not inactivated. This implies that $66 \%$ of the adsorbed phage particles either were not released long enough to become deactivated or that tryptophan was not removable by dilution from the complex (phage + tryptophan $+\mathrm{NaCl}+$ kaolin). 
These experiments with kaolin, in which the rate of adsorption was always slow, suggest that an experiment designed on the lines of Anderson's work to prove activation of the phage by tryptophan is likely to be vitiated by de-activation during the adsorption phase. This was found to be the case; but reference may be made to Table 1 and Fig. 10 showing experiments with bacteria in place of kaolin.

\section{Comparison between the adsorption to phage $0 x 6$, to kaolin and to bacteria}

The effect of $\mathrm{NaCl}$ concentration. Experiments similar to the above but with kaolin replaced by bacteria showed that $\mathrm{NaCl}$ was equally essential for adsorption but that its optimum concentration was higher and the peak concentration less sharply defined, though at about $0 \cdot 10 \mathrm{M}$; Fig. 7 may be compared with Fig. 1 in this respect.

Elution. When phage $\mathrm{Ox} 6$ is adsorbed to bacteria, the phage particle count of the whole uncentrifuged mixture is about the same as the count of the supernatant fluid after centrifugation, showing that all or most of the adsorbed phage particles are permanently inactivated and cannot be eluted unchanged. This inactivation unbalances the equilibrium observed during adsorption to kaolin and results in the



Fig. 4

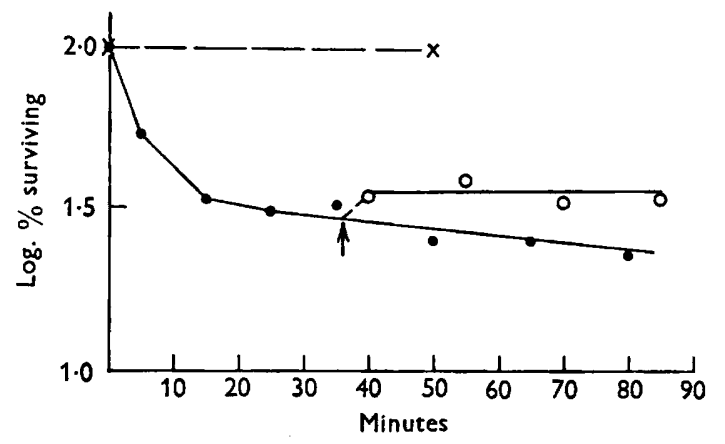

Fig. 5

Fig. 4. Elution of adsorbed phages by adjustment of the $\mathrm{NaCl}$ concentration. $\times$, no kaolin, $0.05 \mathrm{M}-\mathrm{NaCl} ; O$, kaolin with $0.05 \mathrm{M}-\mathrm{NaCl} ; O=$ kaolin with $\mathrm{NaCl}$ increased to $0.35 \mathrm{M}$ at the arrow. All contain tryptophan. The kaolin counts are of supernatant phage after centrifuging.

Fig. 5. Effect on phages adsorbed to kaolin at $40^{\circ}$, of decreasing the temperature to $2^{\circ}$. $x$, No kaolin, $40^{\circ} ; O$, with kaolin, $40^{\circ}$; $O$, with kaolin decreased to $2^{\circ}$ at the arrow. All contain optimal $\mathrm{NaCl}$ and tryptophan. Counts with kaolin are of supernatant phage.

Table 1. The effect of tryptophan concentration on the 'activation' of phage Ox6. Details of experimental mixtures

\begin{tabular}{cccccc}
\multicolumn{6}{c}{ Activation stage } \\
Bottle & $\begin{array}{c}\text { Phage } \\
(\mathrm{ml} .)\end{array}$ & $\begin{array}{c}\text { L-Tryptophan } \\
(\mathbf{8} \mu \mathrm{g} . / \mathrm{ml} .)\end{array}$ & $\begin{array}{c}\text { Tris } \\
(\mathrm{ml} .)\end{array}$ & $\begin{array}{c}\mu \mathrm{g} . \text { L-Trypto- } \\
\text { phan/bottle }\end{array}$ & $\begin{array}{c}\mu \mathrm{g} . \text { L-Trypto- } \\
\text { tophan/ml. }\end{array}$ \\
A & 0.25 & 0.25 & 15.5 & 2 & 0.125 \\
B & 0.25 & 0.25 & 7.5 & 2 & 0.25 \\
C & 0.25 & 0.25 & 3.5 & 2 & 0.5 \\
D & 0.25 & 0.25 & 1.5 & 2 & 1.0 \\
E & 0.25 & 0.25 & 0.5 & 2 & 2.0 \\
F & 0.25 & 0.25 & 0 & 2 & 4.0 \\
G & 0.25 & 0 & 0.25 & 0 & 0 \\
H & 0.25 & 0.25 & 0 & 2 & 4.0
\end{tabular}

\begin{tabular}{|c|c|c|c|c|}
\hline \multicolumn{5}{|c|}{ Adsorption stage } \\
\hline Bottle & $\begin{array}{l}\text { Bact. } \\
\text { (ml.) }\end{array}$ & $\begin{array}{l}\text { Tris } \\
\text { (ml.) }\end{array}$ & $\begin{array}{c}\text { L-Tryptophan } \\
\text { (8 } \mu \mathrm{g} . / \mathrm{ml} .)\end{array}$ & $\begin{array}{l}\text { Final } \mu \mathrm{g} \cdot / \mathrm{ml} \text {. } \\
\text { L-tryptophan }\end{array}$ \\
\hline $\mathbf{A}^{1}$ & 4 & 0 & . - & 0.1 \\
\hline $\mathrm{B}^{1}$ & 4 & 8 & - & 0.1 \\
\hline$C^{1}$ & 4 & 12 & - & 0.1 \\
\hline $\mathrm{D}^{\mathbf{1}}$ & 4 & 14 & - & $0 \cdot 1$ \\
\hline$E^{I}$ & 4 & 15 & - & $0 \cdot 1$ \\
\hline$F^{1}$ & 4 & $15 \cdot 5$ & - & 0.1 \\
\hline $\mathrm{G}^{\mathbf{1}}$ & 4 & $15 \cdot 5$ & - & 0 \\
\hline $\mathrm{H}^{1}$ & 4 & $5 \cdot 75$ & $9 \cdot 75$ & $4 \cdot 0$ \\
\hline
\end{tabular}


linear plot of the $\log \%$ surviving referred to as characteristic of adsorption to bacteria. Figure 8 illustrates these results.



Fig. 6

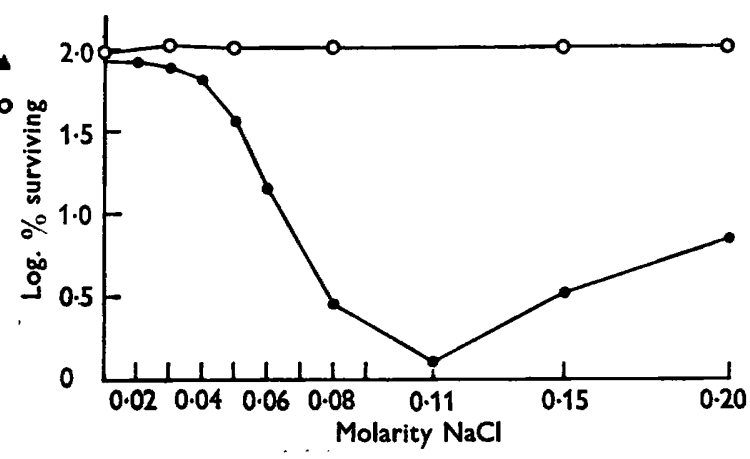

Fig. 7

Fig. 6. Effect on phages adsorbed to kaolin of diluting out tryptophan. $\times, \mathrm{NaCl}$, tryptophan and kaolin (count of whole);, $\mathrm{NaCl}$, tryptophan and kaolin (count of supernatant phage). At the arrow tryptophan was diluted out leaving the same concentrations of $\mathrm{NaCl}$ and kaolin. $\Delta, \mathrm{NaCl}$ and kaolin (count of whole); $\mathrm{O}, \mathrm{NaCl}$ and kaolin (count of supernatant phage).

Fig. 7. Effect of $\mathrm{NaCl}$ concentration on adsorption of phage $\mathrm{Ox} 6$ to bacteria. $O$, No bacteria; 9 , with bacteria (supernatant phage). Both contain tryptophan.

The effect of temperature. The rate of adsorption of phage $0 \times 6$ to bacteria was affected by temperature as was adsorption to kaolin (Fig. 9). It has been stated (cf. Adams 1959) that the proportion of $\mathbf{T} 4$ coli-phage particles adsorbed to bacteria at low temperatures could be increased to equivalence with the proportion at higher temperatures by raising the tryptophan concentration to $100 \mu \mathrm{g} . / \mathrm{ml}$. An effect of this sort was hardly demonstrable with phage $0 x 6$ (Fig. 9). It seems clear that the effect of temperature on adsorption of phage Ox6 to bacteria is exerted through a temperature effect on tryptophan activation, as in the kaolin experiments, but the various elution effects noted with kaolin cannot occur with bacteria because inactivation rapidly follows adsorption.

\section{Activation of phages by tryptophan}

Anderson's (1948) description of the activation of coli phage T4 by tryptophan was largely based on his finding that free phage particles did not produce plaques on a tryptophan-free medium, while adsorbed phage did. It was presumed that the successive bursts on the plate necessary to produce a visible plaque were due to liberation of tryptophan at the first burst. Since all free phages produced plaques on a tryptophan-containing medium, the difference between plaque counts on a tryptophan-containing and a tryptophan-free media was a measure of the number of phage particles adsorbed before plating. His procedure for showing that activation was due to an action of tryptophan on the phage and not on the bacteria was as follows. Equal amounts of coliphage T4 and L-tryptophan were added to each of six tubes but the volumes of the suspensions were adjusted to give a graded series of tryptophan concentration from 0.1 to $4.0 \mu \mathrm{g} . / \mathrm{ml}$. After standing at $37^{\circ}$ for $25 \mathrm{~min}$. to activate the phage, suspensions of coli $\mathbf{B}$ in tryptophan-free medium were added 
to each tube so that the final concentrations of phage particles, bacteria and tryptophan were the same in all. Five minutes were allowed for adsorption to take place and the mixtures were plated on the two media. The counts on the tryptophancontaining medium were the same in all cases, but the counts on the tryptophanfree medium showed a large increase in the number of plaques as the concentration of tryptophan increased in the activation phase of the experiment. 'Since the conditions in the adsorption tubes were identical, the differences in the assays on $F$ agar must have been due to the differences in the concentration of L-tryptophan with

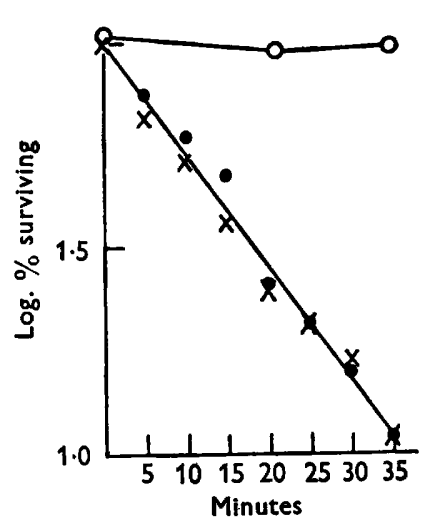

Fig. 8

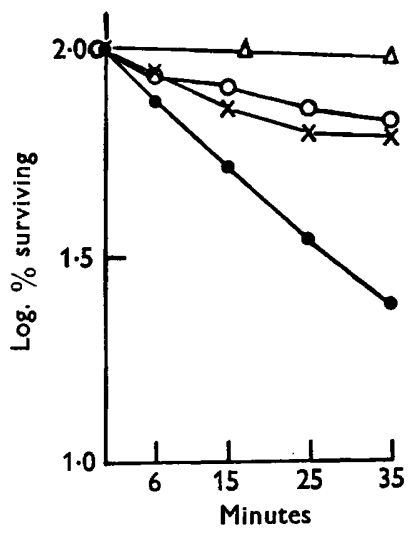

Fig. 9

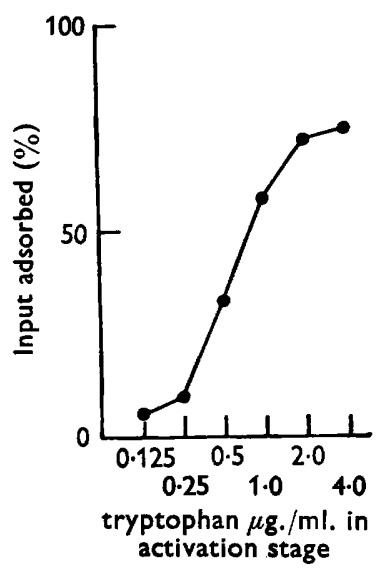

Fig. 10

Fig. 8. Adsorption of phage $0 \times 6$ to bacteria at $40^{\circ}$. $O$, No bacteria; $\odot$, with bacteria (count of whole); $\times$, with bacteria (count of supernatant phage). All contain optimal $\mathrm{NaCl}$ and tryptophan.

Fig. 9. Effect of temperature and of excess tryptophan on adsorption of phage $\mathrm{Ox} 6$ to bacteria. $\triangle$, No bacteria, L-tryptophan $10 \mu \mathrm{g} . / \mathrm{ml} ., 37^{\circ}$; 9 , with bacteria, L-tryptophan $10 \mu \mathrm{g} . / \mathrm{ml} ., 37^{\circ}$ (supernatant phage); $\bigcirc$, with bacteria, L-tryptophan $10 \mu \mathrm{g} . / \mathrm{ml}, \mathbf{2 0}^{\circ}$ (supernatant phage); $\times$; with bacteria, L-tryptophan $100 \mu \mathrm{g} . / \mathrm{ml} ., 20^{\circ}$ (supernatant phage). All contain optimal $\mathbf{~ N a C l}$.

Fig. 10. To show that phage Ox6 pre-treated with tryptophan is 'activated' and no longer dependent upon tryptophan for adsorption

which the virus has been incubated' (Anderson, 1948, fig. 3). Anderson then went on to show that this activation phenomenon was temperature-dependent with an optimum about $35^{\circ}$, that it took about $2 \mathrm{~min}$. to complete, and about the same time to de-activate after removal of the tryptophan. It will be noted that Anderson's observation of the action of tryptophan on a tryp ${ }^{+}$phage which makes it adsorbable is based on inference; it was thought desirable to repeat his crucial experiment to show directly that activation was an essential for adsorption. Table 1 indicates the procedure used; it was based on Anderson's experiments (1948). All materials were dissolved in tris buffer containing $0.1 \mathrm{M}-\mathrm{NaCl}$. The final concentration of bacteria was $3 \times 10^{\circ} / \mathrm{ml}$. Bottles $A$ to $H$ were heated for $20 \mathrm{~min}$ at $37^{\circ}$ for activation and then the contents of bottles $A^{1}$ to $H^{1}$ were poured in. After a further $15 \mathrm{~min}$. the supernatant fluids of all bottles were assayed. Figure 10 shows the adsorption in the various bottles as $\%$ of the bottle $\mathrm{G}$ without tryptophan. As a result of the increasing tryptophan concentration in the activation stage of the experiment the phage 
adsorbed rose from a few particles to $75 \%$. In bottle $H$ the concentration of tryptophan present during the activation phase was maintained at the same value during the adsorption phase and resulted in the phage particles being completely adsorbed. The difference between $\mathrm{H}$ and $\mathrm{F}$ was clearly due to de-activation of free phage in $\mathrm{F}$ by dilution of tryptophan before adsorption could take place. Figure 10 shows the same features as Anderson's (1948) fig. 3.

\section{DISCUSSION}

Kay \& Fildes $(1962 b)$ showed that a heat-labile tryp ${ }^{+}$phage underwent changes in its tail and loss of DNA under three conditions all of which had to operate simultaneously: (i) presence of tryptophan; (ii) presence of $\mathrm{NaCl}$ especially at two optimal concentrations; (iii) an adequate elevation of temperature to control the rate of action. Further (unpublished) work has shown that when similar tests are made in the presence of kaolin, adsorption of the phage takes place (i) in the presence of tryptophan; (ii) in the presence of $\mathrm{NaCl}$ at the lower but not at the higher $\mathrm{NaCl}$ concentration; (iii) at an increase of temperature above $4^{\circ}$ adequate to allow adsorption without heat-inactivation during the period of observation. Kay \& Fildes $(\mathbf{1 9 6 2} b)$ found that discharge of DNA occurred in proportion to the degree of heat inactivation, but we have found (unpublished) that in the presence of kaolin discharge of DNA does not occur. It may be said that under certain conditions the heat-labile phage undergoes changes in its tail tip which result in loss of DNA, while under the same conditions in the presence of kaolin particles the phage becomes adsorbed and does not lose its DNA. It would thus appear that the site of leakage is the same as that of adsorption and highly probable that the nature of the initial change is the same in each case.

In the present work tests of the heat-stable tryp ${ }^{+}$phage, $O \times 6$, have also shown the necessity for the same three conditions to be fulfilled simultaneously before adsorption takes place. Thus the difference between the two phages is that in the heat-labile phage the tail changes in the absence of a recipient go beyond the point of recovery, while in the heat-stable phage the changes are all reversible on removal of any one of the three conditions.

It has been confirmed directly that 'tryptophan-activation' of a tryp ${ }^{+}$phage is due to a temperature-dependent reaction between tryptophan and phage. Since this action is only demonstrable by adsorption, it is not yet clear whether the requirement for $\mathrm{NaCl}$ is in the activation process, in the adsorption process or in both. If, however, the initial lesion in a labile phage which results in loss of DNA is the same as that which 'activates' a phage for adsorption, it follows that $\mathrm{NaCl}$ is necessary in the process of activation.

In the present work the conditions affecting adsorption to kaolin have been compared with those necessary for adsorption to bacteria. The differences between the two types of recipient appear to be: (i) the $\mathrm{NaCl}$ requirement for bacteria is less sharply defined at an optimum concentration; (ii) the adsorption to bacteria is irreversible and therefore the various results of elution are not observed. It is generally accepted that adsorption of phage to bacterium takes place in two steps, the first being reversible and the second not. We have not found strong evidence with phage Ox6 of the existence of a reversible stage owing, no doubt, to the 
rapidity with which the adsorbed phage is inactivated. We therefore prefer to think that the actual adsorption follows much the same course as with kaolin but that the fate of the adsorbed particle subsequent to adsorption is governed by the complex recipient on the bacterial surface.

\section{REFERENCES}

Adams, M. H. (1959). Bacteriophages, pp. 145, 146. London: Interscience Publishers Ltd. Anderson, T. F. (1948). The activation of the bacterial virus T4 by L-tryptophan. $J$. Bact. 55, 637.

Fildes, P. \& KaY, D. (1957). Tryptophan as a bacteriophage adsorption factor. Brit. $J$. exp. Path. 38, 563.

FILDES, P. \& KAY, D. (1959). The function of tryptophan in the adsorption of a bacteriophage. Brit. J. exp. Path. 40, 71.

KAY, D. \& FIldes, P. (1962a). Hydroxymethylcytosine-containing and tryptophandependent bacteriophages isolated from city effluents. J. gen. Microbiol. 27, 143.

KAY, D. \& Fildes, P. (1962b). The thermal lability of tryptophan-dependent bacteriophages. J. gen. Microbiol. $27,147$.

Luria, S. E. (1953). General Virology, p. 165. London: Chapman and Hall. 